\title{
Александров А.Ю. \\ Проблема оценки судом свидетельских показаний в гражданском судопроизводстве
}

ФГБОУ ВО «Калужский государственный университет им. К. Э. Циолковского»

(Россия, Калуга)

doi: 10.18411/trnio-12-2021-159

\section{Аннотация}

Статья посвящена проблеме оценки судом свидетельских показаний применительно к гражданскому судопроизводству. В статье утверждается, что оценка показаний свидетеля судом вызывает определенные сложности с позиции их достоверности. Свидетель, как носитель сведений о фактах, привлекается судом к участию в процессе по инициативе стороны, с которой сам свидетель находится в отношениях, что не может не оказывать влияния на объективность сообщаемой информации. Свидетель, будучи лицом физическим, воспринятую информацию пропускает через собственное сознание, что также влияет на истинность сведений, сообщаемых суду. Законодательство, закрепляющее правовые средства, обеспечивающие достоверность показаний свидетеля, предоставляют суду возможность исключить негодные сведения из числа доказательств, но, тем не менее, нуждаются в совершенствовании.

Ключевые слова: гражданский процесс, судебная истина, доказывание, доказательства, показания свидетеля, достоверность показаний свидетеля, оценка показаний свидетеля, ответственность свидетеля.

\section{Abstract}

The article is devoted to the problem of evaluation by the court of witness testimony in relation to civil proceedings. The article claims that the evaluation of the witness's testimony by the court causes certain difficulties from the standpoint of their reliability. A witness, as a carrier of information about facts, is brought by the court to participate in the process at the initiative of the party with whom the witness himself is in a relationship, which cannot but affect the objectivity of the reported information. The witness, being a physical person, passes the perceived information through his own consciousness, which also affects the truth of the information reported to the court. Legislation that establishes legal means to ensure the reliability of witness testimony provides the court with the opportunity to exclude unsuitable information from the evidence, but, nevertheless, needs to be improved.

Keywords: civil procedure, judicial truth, proof, evidence, witness testimony, reliability of witness testimony, evaluation of witness testimony, witness responsibility.

В юридической литературе по праву свидетельские показания относят к проблемным средствам доказывания, учитывая степень их объективности. Формирование действенного механизма, обеспечивающего достоверность свидетельских показаний, в настоящее время остается весьма актуальным вопросом науки гражданского процессуального права.

В науке гражданского процессуального права участники процесса, не имеющие юридического интереса в исходе дела, относятся к лицам, содействующим осуществлению правосудия. В указанную группу входят свидетели, которые, по смыслу законодателя, должны сообщать суду объективную информацию об обстоятельствах дела.

Но, справедливости ради, следует признать, что объективность или достоверность сведений, исходящих от свидетеля, не могут не вызывать обоснованного сомнения.

Допрос свидетеля инициирует сторона. Вполне разумно утверждать, что, инициируя допрос свидетеля, сторона абсолютно уверена в том, что сведения, полученные в результате допроса свидетеля, будут подтверждать обстоятельства дела, выгодные именной ей и опровергать утверждения ее процессуального противника. Таким образом, между стороной и свидетелем явно присутствует взаимный интерес, который носит не правовой характер, но 
при этом, не может служить основанием для лишения лица статуса свидетеля. В этом случае суду следует быть готовым к определенным трудностям при оценке показаний такого рода свидетеля [7, с. 173]. В силу сказанного, закон, ч. 2 ст. 177 ГПК РФ, обязывает суд до начала допроса свидетеля с целью построения хода допроса и критичности оценки свидетельских показаний выяснить характер отношений между свидетелем и стороной, инициировавшей вызов свидетеля в процесс.

Системное толкование положений, закрепленных в ст. 55, ст. 57, ст. 69 ГПК РФ, позволяют высказать ряд соображений в отношение незаинтересованности свидетеля.

Во-первых, законодатель не закрепляет незаинтересованность свидетеля в качестве обязательного признака.

Во-вторых, определяя правовой статус свидетеля, законодатель не наделил свидетеля признаком абсолютной незаинтересованности в исходе дела.

Свидетель, не являясь стороной спорного материального правоотношения, не имеет ни материального, ни процессуального интереса к исходу процесса, поскольку сам спор не оказывает влияния на его правовой статус. Но связь свидетеля со стороной может носить как внеправовой, основанный на личных отношениях характер (родственный, дружественный и т. д.), так и иной правовой (например, должностные отношения). Безусловно, такое положение не может не оказать воздействие на объективность свидетельских показаний и повлечь критическое отношение суда к их достоверности.

Правовое положение свидетеля непосредственно связано с проблемой объективности свидетельских показаний.

Прежде всего, свидетель, как носитель доказательственной информации, есть лицо физическое, поэтому восприятие, сохранение и воспроизведение в суде информации не может не испытывать субъективного воздействия. Информация, переработанная в сознании субъекта, доводится до суда не в первозданном виде, а переосмысленном, индивидуально переоцененном. В связи с этим, свидетельские показания суду следует рассматривать объективными с определенной долей условности [8, с. 148]. Следовательно, и понятие "истинность" показаний не может быть применима по отношению к свидетельским показаниям в силу субъективной переоценки первозданной информации сознанием свидетеля.

Но показания свидетеля не могут признаваться и исключительно субъективной информацией, т. е. оценочным суждением лица. Следует признать, что чем теснее степень взаимоотношений свидетеля со стороной, тем более явно проступает заинтересованность свидетеля в исходе дела [4, с. 12], и тем критичнее суду следует подходить к оценке полученной от свидетеля информации. Эту позицию разделяет и Верховный Суд Российской Федерации [6].

Однако, если свидетельские показания не противоречат другим доказательствам по делу, то априори ставить показания свидетеля под сомнение не стоит. Суд, руководствуясь ст. 67 ГПК РФ, оценивает доказательства в их совокупности, следовательно, вывод суда об обстоятельствах дела опирается на достаточное количество достоверных доказательств, способных как подтвердить, так и опровергнуть показания свидетеля.

Суду, оценивая объективность информации, полученной от свидетеля, следует обращать внимание также и на возраст свидетеля.

С гносеологической точки зрения свидетель - это физическое лицо, способное в силу физического и психического развития воспринимать, сохранять и воспроизводить информацию, ставшую ему известной, как очевидцу, и необходимой для рассмотрения дела. Исходя из утверждения, изложенного выше, законодатель вполне оправдано не устанавливает предельные возрастные рамки для свидетеля, но по отношению к несовершеннолетним устанавливает определенные особенности. Допрос несовершеннолетних возможен с участием педагога и законных представителей, что обусловлено спецификой детского возраста. Участие педагога, в том смысле, как это 
закреплено ст. 179 ГПК РФ, надо толковать шире, с учетом современных реалий, понимая под педагогом, в том числе, и психолога.

Поскольку полностью исключить правовыми средствами субъективный фактор из показаний свидетеля не представляется возможным, законодатель предпринял ряд правовых шагов, ограничивающих возможность использования свидетельских показаний в качестве доказательств там, где требование объективности и достоверности доказательств наиболее актуально. На пример свидетельские показания являются недопустимыми при нарушении положений о простой письменной форме сделки в соответствии со ст. 162 ГК РФ.

Системное толкование норм права, закрепляющих правовой статус свидетеля и процессуальный порядок исследования и оценки свидетельских показаний, а также правовые гарантии обеспечения достоверности информации, получаемой судом от свидетеля как источника сведений об обстоятельствах дела, позволяют сделать вывод о том, что наиболее эффективным средством обеспечения достоверности предоставленной суду информации является наличие уголовного преследования в отношение свидетеля.

Гражданское процессуальное законодательство, ч. 2 ст. 70 ГПК РФ, закрепляет положение, согласно которому свидетель за отказ от дачи и дачу заведомо ложных показаний подлежит привлечению к уголовной ответственности согласно ст. 307 и ст. 308 Уголовного кодекса Российской Федерации.

Введение уголовной ответственности за отказ от дачи показаний следует рассматривать как механизм обеспечения полноты доказательственной базы, и в целом на объективность показаний свидетеля не влияющий.

Ровно наоборот следует понимать привлечение к уголовной ответственности за дачу заведомо ложных показаний. Сообщение свидетелем суду умышленно искаженной, не соответствующей истинности информации об обстоятельствах дела в пользу одной из сторон материально-правового спора создает угрозу правильности оценки спорного правоотношения в целом, и как результат, влечет вынесение неверного решения по существу.

Считаю необходимым уточнить, что основанием для привлечения к уголовной ответственности за дачу заведомо ложных показаний, является сообщение суду ложной информации только в отношение обстоятельств дела. Сообщение же иной, не относящейся к спорному правоотношению, хотя и заведомо ложной информации не образует состава преступления.

Оценивая показания свидетеля суд, по смыслу закона, исходит из предположения истинности информации, поскольку страх уголовного преследования побуждает свидетеля сообщать суду только достоверные сведения о фактах.

Иными словами, пока приговором суда, вступившим в законную силу, не доказана заведомая ложность сведений, полученных от конкретного свидетеля, его показания предполагаются истинными и подлежат исследованию и оценке наряду и в совокупности с другими доказательствами, имеющимися в материалах дела.

Но суд исключает из числа доказательств не только заведомо ложные показания свидетеля, но и показания свидетеля ложность которых стала следствием искреннего заблуждения. Являются ли показания заведомо ложными, или это искреннее заблуждение свидетеля в отношении фактов, для рассмотрения спора значения не имеет. Это имеет значение лишь в отношение решения вопроса об уголовном преследовании. В любом случае такие показания свидетеля бесспорно подлежат исключению из числа доказательств.

Закрепленная законодателем и приведенная выше правовая конструкция обязывает суд при оценке показаний свидетеля учитывать их субъективный характер.

В юридической литературе нет единой позиции в отношение вопроса о том, можно ли рассматривать уголовную ответственность за дачу заведомо ложных показаний как эффективную превентивную меру, обеспечивающую суд достоверной информацией, получаемой от свидетеля, 
А. И. Жиляев полагает, что привлечение к уголовной ответственности не является определяющим фактором, стимулирующим свидетеля сообщать суду правдивую информацию [1, с. 13].

Безусловно, возможное уголовное преследование не выступает единственным фактором, определяющим поведение свидетеля. В юридической литературе даже высказывается предложение исключить уголовную ответственность за дачу заведомо ложных показаний, отнеся ее к разряду административных проступков [3, с. 54]. Считаю, это преждевременным. Отказ свидетеля от дачи показаний или дача заведомо ложных показаний искажает выводы суда об обстоятельствах дела, приводит к вынесению неверного решения, и, тем самым, исключает достижения целей гражданского судопроизводства, закрепленных в ст. 2 ГПК РФ. Уголовное наказание следует сохранить, но применят как крайнее средство [5].

Основополагающим принципом гражданского судопроизводства выступает принцип диспозитивности, в равной мере определяющий поведение всех участников процесса, в том числе и свидетеля. Свидетель, как лицо, содействующее осуществлению правосудия, должно осознавать значимость своего участия в процессе, понимать как положительные, так и отрицательные последствия совершаемых действий.

Правильной оценке судом свидетельских показаний также способствует закрепленный процессуальный порядок допроса свидетеля, который суд обязан уметь эффективно применять [9, с. 78].

Гражданское процессуальное законодательство вменяет суду обязанность, прежде всего, установить характер отношений свидетеля с участниками процесса, особенно со сторонами, дать свидетелю возможность в свободной форме изложить известные ему сведения о фактах, предоставляет суду возможность с помощью дополнительных вопросов уточнить сведения о фактах, устранить неточности и противоречия, а в необходимых случаях провести повторный допрос.

Заслуживает внимания предложение В. В. Молчанова о закреплении в процессуальном законодательстве обязанности свидетеля перед дачей показаний приносить присягу с обещанием сообщать суду только правду и личной подписью скреплять протокол судебного заседания, содержащий его показания [2, с. 323].

Полагаю, предложенная новелла положительно скажется на объективности свидетельских показаний, будет способствовать повышению уровня ответственности свидетеля, как участника процесса.

$$
* * *
$$

1. Жиляев А.И. Криминологическая характеристика и предупреждение заведомо ложных показаний свидетелей и потерпевших: Автореф. дис. ... канд. юрид. наук. Н. Новгород, 2002.-30 с.

2. Молчанов В. В. Развитие учения о свидетелях и свидетельских показаниях в гражданском процессе: диссертация ... доктора юридических наук: 12.00.15 / Молчанов Валерий Владимирович; [Место защиты: Моск. гос. ун-т им. М.В. Ломоносова]. - Москва, 2009.- 451 с.

3. Намнясева В. В. Проблемные вопросы уголовной ответственности за отказ от дачи показаний // Юридическая наука и правоохранительная практика. 2015. №1 (31). - 49-59 с.

4. Опалич Е.В. Проблемы конкретизации статуса отдельных участников гражданских процессуальных правоотношений // Арбитражный и гражданский процесс. 2016. № 6.- 11-14 с.

5. Определение Конституционного Суда РФ от 10 июля 2003 г. N 270-О «Об отказе в принятии к рассмотрению запроса Курганского городского суда Курганской области о проверке конституционности части первой статьи 3, статьи 10 Уголовного кодекса Российской Федерации и пункта 13 статьи 397 Уголовно-процессуального кодекса Российской Федерации» // СПС Гарант (Дата обращения: 14.11.2021)

6. Определение ВС РФ от 26.08.2008 № 5-В08-88 // Бюллетень Верховного Суда РФ. 2009. № 6. (Дата обращения: 15.10 .2021$)$

7. Треушников М. К. Судебные доказательства: моногр. / М. К. Треушников. - Изд. 4-е, испр. и доп. - М., 2005.268 c.

8. Фатнева Е. С. Свидетель как источник доказательства по делу // Символ науки. 2017. №5.- 148-151 с.

9. Чебыкина Ю.О. Проблемы использования свидетельских показаний в качестве средства доказывания в гражданском и арбитражном процессе // Наука без границ. 2017. №5 (10). - 76-81 с. 